Document downloaded from:

http://hdl.handle.net/10251/122503

This paper must be cited as:

Olmeda, P.; García Martínez, A.; Monsalve-Serrano, J.; Lago-Sari, R. (2018). Experimental investigation on RCCl heat transfer in a light-duty diesel engine with different fuels:

Comparison versus conventional diesel combustion. Applied Thermal Engineering. 144:424436. https://doi.org/10.1016/j.applthermaleng.2018.08.082

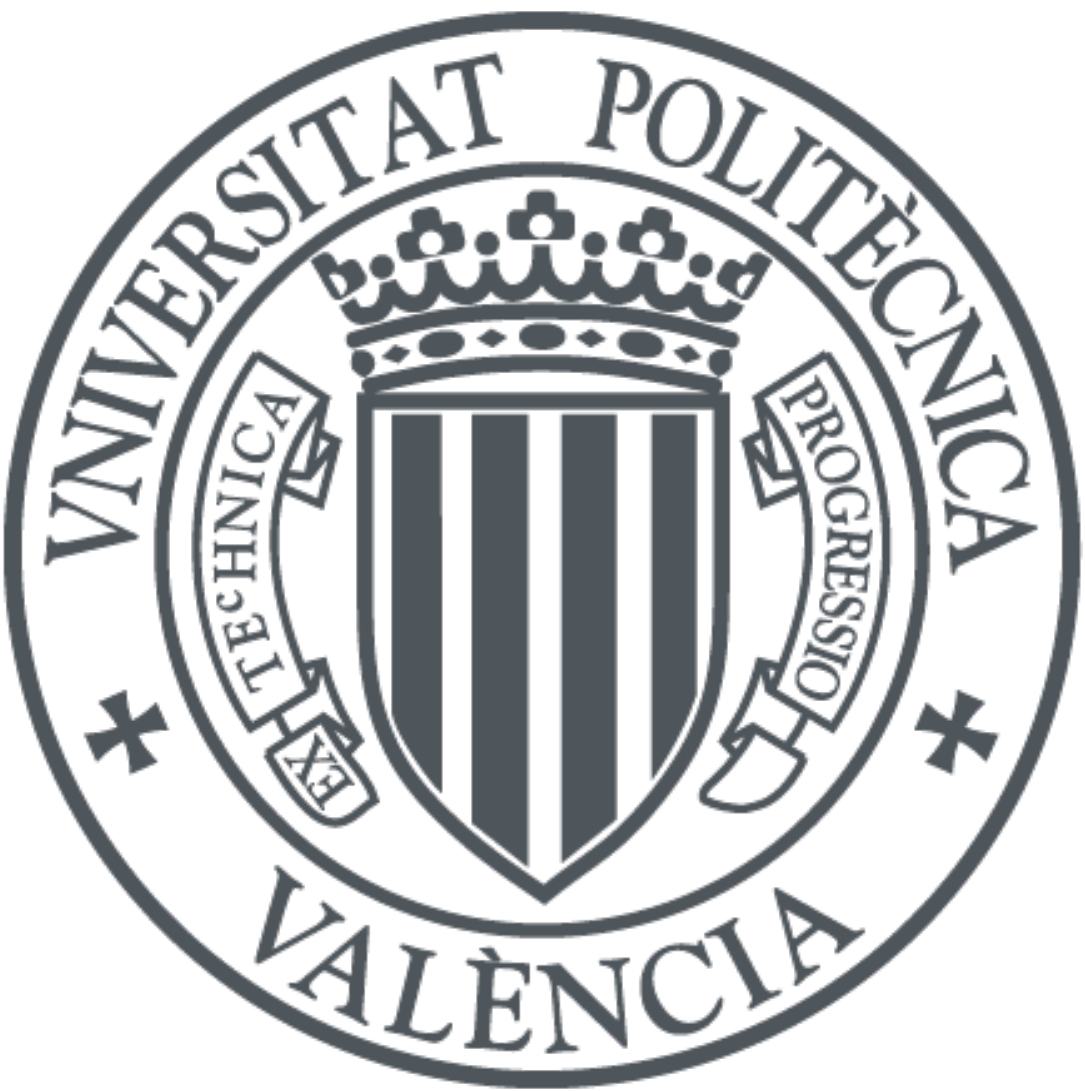

The final publication is available at

http://doi.org/10.1016/j.applthermaleng.2018.08.082

Copyright Elsevier

Additional Information 


\section{Experimental investigation on RCCI heat transfer in a light-duty diesel engine with different fuels: comparison versus conventional diesel combustion}

Applied Thermal Engineering, Volume 144, 5 November 2018, Pages 424-436

https://doi.org/10.1016/j.applthermaleng.2018.08.082

Pablo Olmeda, Antonio García*, Javier Monsalve-Serrano and Rafael Lago Sari

CMT - Motores Térmicos, Universitat Politècnica de València, Camino de Vera s/n, 46022 Valencia, Spain

Corresponding author $\left({ }^{*}\right)$ :

Dr. Antonio García Martínez (angarma8@mot.upv.es)

Phone: +34963876574

Fax: +34 963876574

\section{Abstract}

Reactivity controlled compression ignition ( $\mathrm{RCCl}$ ) combustion has demonstrated to be able to avoid the NOx-soot trade-off appearing during conventional diesel combustion (CDC), with similar or better thermal efficiency than CDC under a wide range of operating conditions. The high thermal efficiency of $\mathrm{RCCl}$ is explained by the combination of a short-duration and well-phased combustion process, which maximizes the fuel-to-work conversion efficiency, together with relatively low combustion temperatures, which increases the specific heat ratio during expansion and reduces thermal gradients for heat transfer losses. The objective of this work is to study the RCCI heat transfer characteristics and compare them to those of the $\operatorname{DC}$ regime. To do this, a single-cylinder light-duty research engine instrumented with $25 \mathrm{~K}$-type thermocouples distributed among the cylinder head and cylinder liner is used. First, the influence of some engine settings on the $\mathrm{RCCl}$ heat transfer phenomenon is explored by means of parametric sweeps. Later, the $\mathrm{RCCl}$ heat transfer characteristics are compared for two different low reactivity fuels (LRF), gasoline and E85. Finally, the heat transfer characteristics of $\mathrm{RCCl}$ and $\mathrm{CDC}$ combustion regimes are compared at some representative operating points in matched load conditions. The results show that both LRF tested are suitable to be used in RCCI giving similar results in terms of energy usage. Moreover, the ability of $\mathrm{RCCl}$ combustion in exploiting the fuel energy to extract useful work is demonstrated, reducing by $13 \%$ the heat transfer versus CDC.

\section{Keywords}

Reactivity controlled compression ignition; Dual-fuel combustion; Efficiency; Internal combustion engine; ethanol

\section{Introduction}

Internal combustion engines (ICE) are the most widely used powertrain source for transportation purposes worldwide [1]. Among the different engine technologies available in the market, compression ignition $(\mathrm{Cl})$ engines lead the transportation sector because they offer a high thermal efficiency and performance [2]. However, the high levels of nitrogen oxides (NOx) and smoke emissions occurring during the conventional diesel combustion (CDC) process are reducing the social acceptance of this engine platform in the recent years [3]. Those pollutants worsen the air quality in the cities, 
which is forcing the appearance of new regulations to obtain environmentally friendlier ICE-powertrains [4]. To accomplish the emissions regulations, the engine manufacturers rely on using aftertreatment systems to reduce the emissions generated during the combustion process before being emitted to the atmosphere [5]. This approach entails adding three main systems to mitigate the emissions from diesel engines, the selective catalyst reduction (SCR) system for NOx emissions, diesel particulate filter (DPF) to remove the soot content in the exhaust gas, and the diesel oxidation catalyst (DOC) to reduce hydrocarbons $(\mathrm{HC})$ and carbon monoxide $(\mathrm{CO})$ emissions [6], and improve the soot oxidation in the DPF through the $\mathrm{NO}_{2}$ generation [7]. Since the addition of these systems increases the complexity and total cost of the vehicle, alternative combustion strategies to CDC are being studied nowadays to reduce the emissions generation during the combustion process [8].

From the NOx and soot emissions standpoint, literature demonstrates that the low temperature combustion (LTC) concepts are much cleaner than CDC [9]. The LTC strategy differs from CDC in that LTC relies on decoupling the end of injection (EOI) of the direct injected fuel and the start of combustion (SOC) [10]. This promotes a highly diluted air-fuel charge inside the cylinder before the SOC [11], which enables a simultaneous reduction of NOx and soot emissions over a wide range of engine speeds and loads [12].

Homogeneous charge compression ignition $(\mathrm{HCCl})$ is the oldest premixed LTC strategy. $\mathrm{HCCl}$ operation with diesel fuel has been widely studied by many researchers in the past years [13]. It was demonstrated that the high levels of charge dilution achieved using high exhaust gas recirculation (EGR) rates together with very early injection timing, allows reducing the NOx and soot emissions to near zero levels [14]. Moreover, the thermal efficiency with $\mathrm{HCCl}$ is higher than with $\mathrm{CDC}$ due to the rapid combustion processes obtained because of the homogeneous fuel-air mixture [15]. As a counterpart, the feasible operating range with this strategy was found to be very small due to the lack of combustion control as the engine load increases [16]. In this sense, as the incylinder pressure and temperature increase with the engine load, the start of combustion, governed by chemical kinetics, was found to occur during the early compression stroke, which causes high pressure gradients and combustion noise [16]. Another drawback found with $\mathrm{HCCl}$ was related to the cold start process and the excessive $\mathrm{CO}$ and unburned $\mathrm{HC}$ levels [17], both limiting its potential to be implemented in real engines.

To minimize the main drawbacks found with $\mathrm{HCCl}$, the partially premixed combustion (PPC) concept was proposed [18]. In this case, the injection timing is delayed compared to $\mathrm{HCCl}$ with the aim of promoting a stratified (less homogeneous) in-cylinder air-fuel mixture [19]. The reactivity stratification in the combustion chamber leads to a more sequential autoignition process than $\mathrm{HCCl}$, which increases the degree of combustion control [20]. This allows reducing the combustion noise and maximum excessive pressure rise rates (PRR), and therefore increasing the effective operating range [21]. However, it was found that the high reactivity of the diesel fuel limits the potential for extending the operating range of the PPC concept towards high loads. Bessonete et al. [22] suggested that proper operation with premixed LTC concepts at low load would require using low octane fuels (diesel-like), while for operating at high loads would be necessary high octane fuels (gasoline-like). Following these findings, Kalghatghi et al. 
[23] proposed the gasoline PPC concept. Several studies demonstrate that the use of gasoline fuel in the PPC mode extends the ignition delay and allows better control of the combustion process as load increases [24]. However, the operation at low load was found to be compromised when gasoline fuels with octane number (ON) higher than 91 are used [25]. The use of a spark plug to control the gasoline PPC combustion process at low load was found to be a possible alternative [26]. However, the benefits in terms of NOx and soot emissions that characterize the LTC concepts disappeared due to the need of rich local equivalence ratios between the spark plug electrodes [27].

Following the findings reported by Bessonete et al. [22], Inagaki et al. [23] proposed a dual-fuel premixed compression ignition ( $\mathrm{PCl}$ ) combustion strategy using two fuels with different reactivity. In this combustion concept, the fuels are injected into the cylinder using two separated injector systems, so that the quantity of each fuel can be varied independently depending on the engine operating conditions. By means of experimental tests, the authors confirmed an excellent control of the combustion process and extremely low NOx and soot emissions. Nowadays, this combustion concept is known as reactivity controlled compression ignition ( $\mathrm{RCCl}$ [ [28], and it is being widely investigated by the research community. In RCCl, the LRF is injected in the intake port using a port fuel injector (PFI) and the high reactivity fuel (HRF) is injected using a direct injector (DI) [29]. The typical fuels used to implement the RCCl concept are diesel and gasoline because of their availability in the market [30], but many other alternative fuels have been tested successfully under RCCl conditions [31][32][33]. As literature demonstrates, if simultaneous low NOx and soot emissions and high efficiency are wanted, the percentage between the HRF and LRF should vary with the engine conditions [34]. At low load, the LRF quantity must be low to increase the combustion stability and reduce the $\mathrm{HC}$ and $\mathrm{CO}$ emissions. At medium load, the LRF portion reaches their maximum levels, with values near $85 \%$ in mass. At high loads, the LRF portion must be moderated to avoid excessive PRR and maximum in-cylinder pressures [35]. Following this approach, the $\mathrm{RCCl}$ has been demonstrated to be capable of reaching the steady-state NOx and soot levels imposed by the EURO VI regulation without aftertreatment necessities under different engine platforms [36][37][38].

The main reasons for the high efficiency achieved with the LTC concepts are common for all the concepts. First, due to the homogeneity of the gas charge properties, rapid combustion events occur when the proper in-cylinder thermodynamic conditions are reached [39]. The fast combustion process, if well phased in the engine cycle, maximizes the fuel-to-work conversion efficiency [40]. Second, the increase of the charge uniformity with LTC makes the global and local temperatures distribution inside the cylinder to be more similar than with CDC [41], avoiding elevated local temperatures near the piston and cylinder walls. This reduces the heat transfer losses due to localized effects [42]. The objective of this work is to study the RCCl heat transfer characteristics and compare them to those of the CDC regime. To do this, a single-cylinder light-duty research engine instrumented with $25 \mathrm{~K}$-type thermocouples is used. From these, 13 thermocouples are located in the cylinder head, while the remaining ones are installed in the cylinder liner. The temperature measurement from the thermocouples allows to calculate the surface heat flux, dynamic heat transfer, and surface temperature occurring during the engine tests. First, the influence of some engine parameters on the $\mathrm{RCCl}$ heat transfer process is evaluated by means of parametric sweeps. Later, the RCCI 
heat transfer characteristics are explored for two different LRF, 98 ON gasoline and E85, using E590 diesel as high reactivity fuel. Finally, the heat transfer characteristics of RCCI and $C D C$ combustion regimes are compared at some representative operating points in matched load conditions.

\section{Materials and methods}

\subsection{Engine, test cell and fuels description}

The experiments were carried out in a single-cylinder diesel engine (SCE) based on a production light-duty $1.9 \mathrm{~L}$ platform. The engine has four valves driven by dual overhead cams. The piston used is the production one, with a re-entrant bowl that confers a geometric compression ratio of 17.1:1. The swirl ratio was fixed at 1.4 using the tangential and helical valves located in the intake port [43], which is a representative value of that used in the stock engine configuration. The Table 1 summarizes the more relevant characteristics of the engine.

Table 1. Engine characteristics.

\begin{tabular}{|c|c|}
\hline Engine Type & 4 stroke, 4 valves, direct injection \\
\hline Number of cylinders [-] & 1 \\
\hline Displaced volume $\left[\mathrm{cm}^{3}\right]$ & 477 \\
\hline Stroke $[\mathrm{mm}]$ & 90.4 \\
\hline Bore $[\mathrm{mm}]$ & 82 \\
\hline Piston bowl geometry [-] & Re-entrant \\
\hline Compression ratio [-] & 17.1:1 \\
\hline Rated power [kW] & $27.5 @ 4000 \mathrm{rpm}$ \\
\hline Rated torque [Nm] & $80 @ 2000-2750$ rpm \\
\hline
\end{tabular}

The fuel injection system was adapted to allow $\mathrm{RCCl}$ operation as shown in Figure 1. As sketched, the EN590 diesel fuel was injected into the cylinder by means of a centrally located solenoid direct injector coupled with a common-rail fuel injection system. The injection settings were managed using a DRIVVEN controller. The LRF (gasoline or E85) was fumigated in the intake manifold using a PFI located $160 \mathrm{~mm}$ far from the intake valves, which was governed through a Genotec unit. The mass flow rate of both fuels was measured using dedicated AVL 733S fuel balances. The main characteristics of the DI and PFI are depicted in Table 2, and the most relevant properties of the high and LRF used in this study are summarized in Table 3.

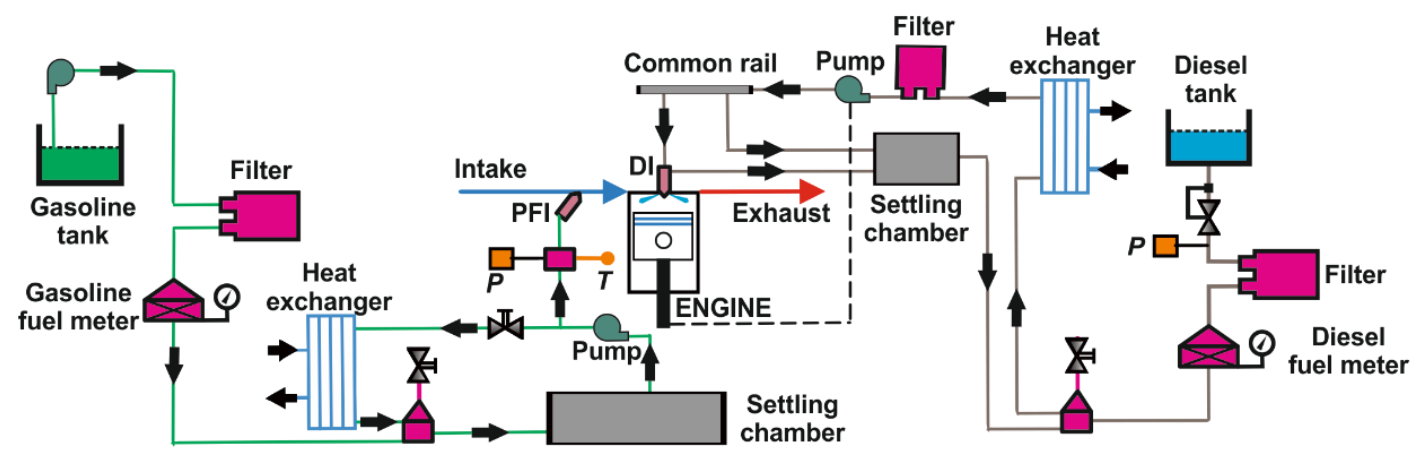

Figure 1. Fuel injection systems scheme. 
Table 2. Characteristics of the direct and port fuel injector.

\begin{tabular}{|l|c|l|c|}
\hline \multicolumn{2}{|c|}{ Direct injector } & \multicolumn{2}{c|}{ Port fuel injector } \\
\hline Actuation Type [-] & Solenoid & Injector Style [-] & Saturated \\
\hline Steady flow rate @ 100 bar $\left[\mathrm{cm}^{3} / \mathrm{min}\right]$ & 880 & Steady flow rate @ 3 bar [cm $3 / \mathrm{min}]$ & 980 \\
\hline Included spray angle $\left[{ }^{\circ}\right]$ & 148 & Included Spray Angle [ $\left.{ }^{\circ}\right]$ & 30 \\
\hline Number of holes [-] & 7 & Injection Strategy [-] & single \\
\hline Hole diameter [ $\mu \mathrm{m}]$ & 141 & Start of Injection [CAD ATDC] & 340 \\
\hline Maximum injection pressure [bar] & 1600 & Maximum injection pressure [bar] & 5.5 \\
\hline
\end{tabular}

Table 3. Physical and chemical properties of the fuels.

\begin{tabular}{|l|c|c|c|}
\cline { 2 - 4 } \multicolumn{1}{c|}{} & Diesel EN590 & Gasoline & E85 \\
\hline Density $\left[\mathrm{kg} / \mathrm{m}^{3}\right]\left(\mathrm{T}=15^{\circ} \mathrm{C}\right)$ & 842 & 747 & 781 \\
\hline Viscosity $\left[\mathrm{mm}^{2} / \mathrm{s}\right]\left(\mathrm{T}=40^{\circ} \mathrm{C}\right)$ & 2.929 & 0.545 & - \\
\hline RON [-] & - & 97.6 & 108 \\
\hline MON [-] & - & 89.7 & 89 \\
\hline Ethanol content [\% vol.] & - & - & 84.7 \\
\hline Cetane number [-] & 51 & - & - \\
\hline Lower heating value $[\mathrm{MJ} / \mathrm{kg}]$ & 42.50 & 44.09 & 31.56 \\
\hline
\end{tabular}

The scheme of test cell in which the engine is operated is shown in Figure 2. An electric dynamometer is used for the engine speed and load control during the experiments. The air intake line is composed of a screw compressor that feeds the engine with fresh air at a pressure up to 3 bar, heat exchanger and air dryer to modify the temperature and relative humidity of the air, airflow meter and a settling chamber sized to attenuate the pulsating flow. Moreover, pressure and temperature transducers are instrumented in this element with regulation purposes. The EGR is introduced in the intake line, downwards the settling chamber, through a dedicated line composed of a heat exchanger, settling chamber and regulation valve. EGR temperature is monitored in several points along the line for its control. Finally, the pressure and temperature of the air-EGR mixture are measured in the intake manifold before entering to the cylinder.

The first elements of the exhaust line are the pressure and temperature transducers located in the exhaust manifold. After them, a settling chamber is installed to attenuate the exhaust flow before the EGR bypass. Later a pneumatic valve is used to reproduce the backpressure provoked by the turbocharger in the real multi-cylinder engine. The last elements of the exhaust line are the emissions analyzers. A five-gas Horiba MEXA7100 DEGR analyzer is used to measure the gaseous engine-out emissions. Each steadystate operating points is measured three times along a period of 60 seconds. Finally, an AVL 415S smoke meter is used to measure the smoke emissions in filter smoke number (FSN) units. Three consecutive measurements of 1 liter volume each with paper-saving mode off were took at each engine operating point. The accuracy of the main elements of the test cell is shown in Table 4. 


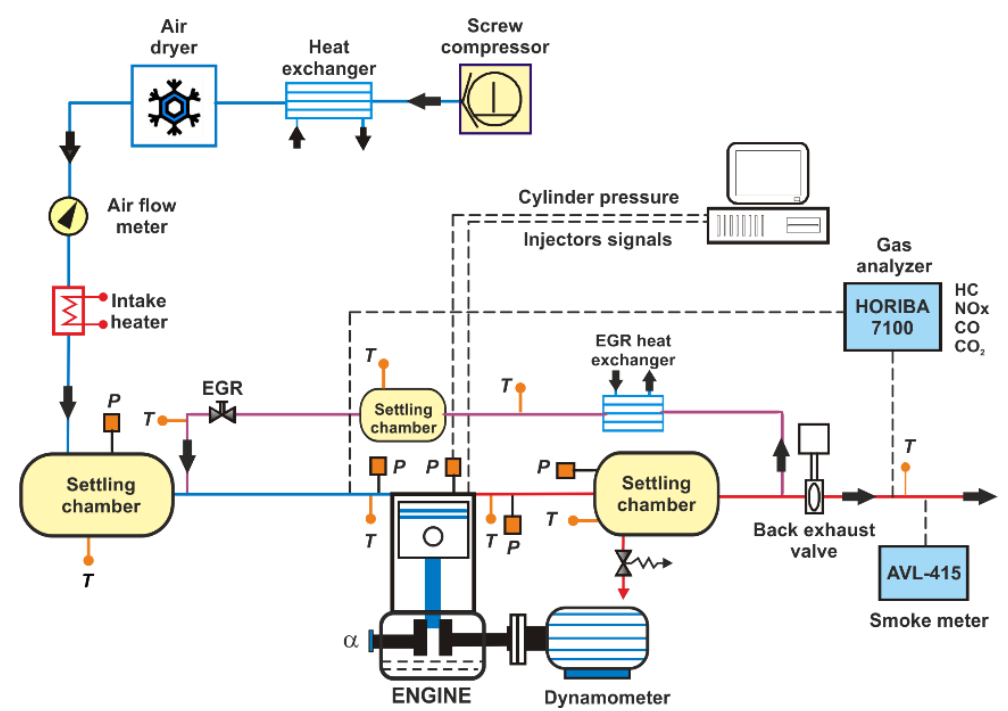

Figure 2. Test cell scheme.

Table 4. Accuracy of the instrumentation used in this work.

\begin{tabular}{|l|l|l|l|}
\hline Variable measured & Device & Manufacturer / model & Accuracy \\
\hline In-cylinder pressure & Piezoelectric transducer & Kistler / 6125BC & \pm 1.25 bar \\
\hline Intake/exhaust pressure & Piezorresistive transducers & Kistler / 4603B10 & \pm 25 mbar \\
\hline $\begin{array}{l}\text { Temperature in settling } \\
\text { chambers and manifolds }\end{array}$ & Thermocouple & TC direct / type K & $\pm 2.5^{\circ} \mathrm{C}$ \\
\hline Crank angle, engine speed & Encoder & AVL / 364 & \pm 0.02 CAD \\
\hline $\mathrm{NOx}, \mathrm{CO}, \mathrm{HC}, \mathrm{O}_{2}, \mathrm{CO}_{2}$ & Gas analyzer & $\begin{array}{l}\mathrm{HORIBA} / \mathrm{MEXA} 7100 \\
\text { DEGR }\end{array}$ & $4 \%$ \\
\hline FSN & Smoke meter & AVL / 415 & $\pm 0.025 \mathrm{FSN}$ \\
\hline Gasoline/diesel fuel mass flow & Fuel balances & AVL / 733S & $\pm 0.2 \%$ \\
\hline Air mass flow & Air flow meter & Elster / RVG G100 & $\pm 0.1 \%$ \\
\hline
\end{tabular}

\subsection{Instrumentation for wall temperature measurement}

The metallic parts around the combustion chamber of the engine are instrumented with $25 \mathrm{~K}$-type thermocouples allowing to obtain measurements up to $1300{ }^{\circ} \mathrm{C}$ with an accuracy of $0.75 \%$ of the measurement, whose location is illustrated in Figure 3 . The cylinder head has installed 13 thermocouples, distributed in two sections perpendicular to the cylinder axis, located at $4 \mathrm{~mm}$ and $7 \mathrm{~mm}$ above the fire deck surface. The distribution of the thermocouples at those geometric planes can be seen in Figure 3 (left and middle). The cylinder liner has embedded 12 thermocouples located at different distances along the piston stroke (Figure 3, right). The cylinder has four columns of three thermocouples each separated 90 degrees from each other. These thermocouples were inserted through holes drilled directly in the engine structure. The radial distance between the inner surface of the liner and each thermocouple is $1.3 \mathrm{~mm}$. The signals from the thermocouples were acquired by two data-loggers using an acquisition frequency of $1 \mathrm{~Hz}$ and then sent to be recorded on a computer. For each operating condition a total time of 20 minutes was waited before the data acquisition to guarantee the thermal stabilization of the engine. The respective thermocouples numbers presented in the Figure 3 will be used as references during the validation and result sections. 

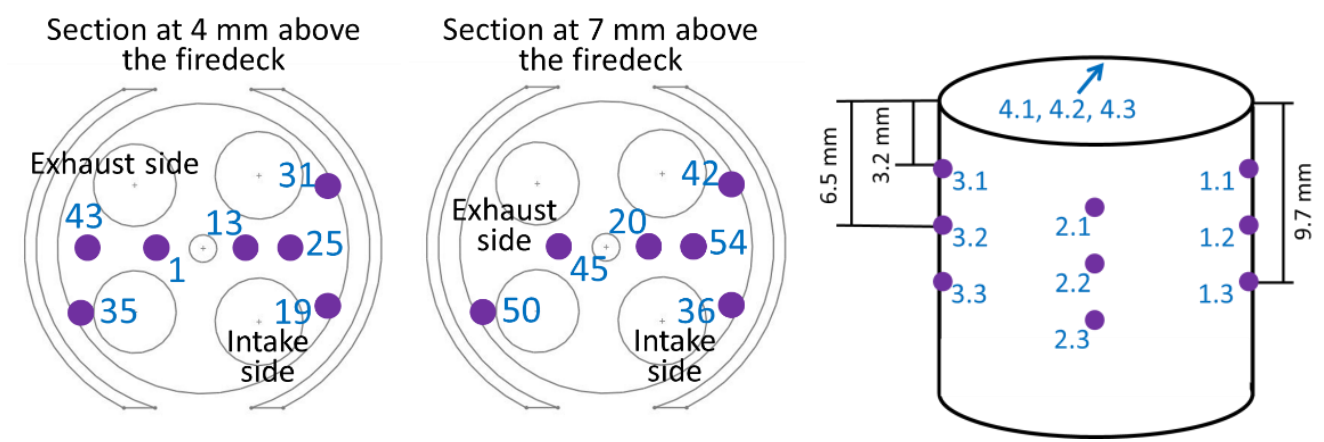

Figure 3. Location of the different thermocouples used in the cylinder head (left and middle) and cylinder liner (right).

\subsection{Numerical modelling and calibration procedure}

There are different paths that the energy from the injected fuel can follow during the thermodynamic cycle. They can be enumerated as work output (that can be defined as net or gross energy whenever the pumping losses are accounted or not), exhaust losses, heat transfer losses and combustion inefficiency. The work output can be quantified by means of the instantaneous in-cylinder pressure measurement, while the combustion losses can be estimated through the exhaust gas concentrations, as shown in Equation 1 [44]. The heat transfer and exhaust losses are of major importance for maximizing the overall engine cycle efficiency.

$$
\text { Comb.Eff. }=\left(1-\frac{H C}{m_{f}}-\frac{C O}{4 \cdot m_{f}}\right) \cdot 100
$$

The premixed LTC combustion modes, as $\mathrm{RCCl}$, are characterized by short combustion durations with low temperatures. This leads to small thermal gradients, resulting in lower heat transfer losses than CDC. Nonetheless, quantifying these improvements is difficult, since it is required a large number of outputs. In the light of this, a finite volume based computational engine model was developed in GT Power to quantify the effects that fundamental $\mathrm{RCCl}$ settings have on the energy paths. The model includes geometric information from the experimental setup (pipes length, discharge coefficient and lift from the valves, injection pattern...) as well as a template that allows to specify the 3-D geometry from the piston, cylinder head and liner. Pressure and temperature boundary conditions for flow and thermal calculations were acquired experimentally and used to represent the operating condition. The flow field and temperature distribution is calculated along the pipes during the period that comprehends the gas exchange process. From the inlet valve close (IVC) event until the exhaust valve opening (EVO), the calculation model relies on using the in-cylinder pressure profile to determine the experimental heat release rate by the three-pressure analysis (TPA) routine. Detailed information about this GT Power template can be found in [45]. This process allows to determine the instantaneous heat release according to a thermodynamic balance calling the first law of thermodynamics applied in a closed volume. In addition, the exhaust gas concentrations from the experiments can be specified and used to quantify the combustion efficiency. Finally, the heat transfer losses can be determined by using a proper heat transfer model that accounts for the convective and conductive mechanisms whilst the exhaust losses are determining subtracting the other terms [46]. 
The convective heat transfer coefficient was determined using a method proposed by Morel and Keribar [47], which consists of determining the heat transfer coefficient spatially and time resolved. The model consists of dividing the combustion chamber in macro zones and, afterwards, to solve the conservation equations of mass, momentum and energy. More details about the model can be found in [47]. The conductive heat transfer solution relies on using a finite elements approach. For this, it is necessary to specify an approximate geometry, inserting the characteristics dimensions for the piston, liner, valves and cylinder head with their respective materials. An outer boundary condition describing the cooling substance and its temperature is also needed.

Different cases were simulated, comparing the predicted values to the experimental results to verify the agreement between them. For the sake of brevity, only one comparison case will be presented and discussed here. As it can be seen in Figure 4, the pressure versus volume profiles presents good agreement in both gas exchange process and high pressure phase. The proper agreement between the simulated and experimental results during the compression stroke are of major importance, since this indicates similarity for trapped values and state properties. This statement can be also extended to the combustion and expansion stroke.

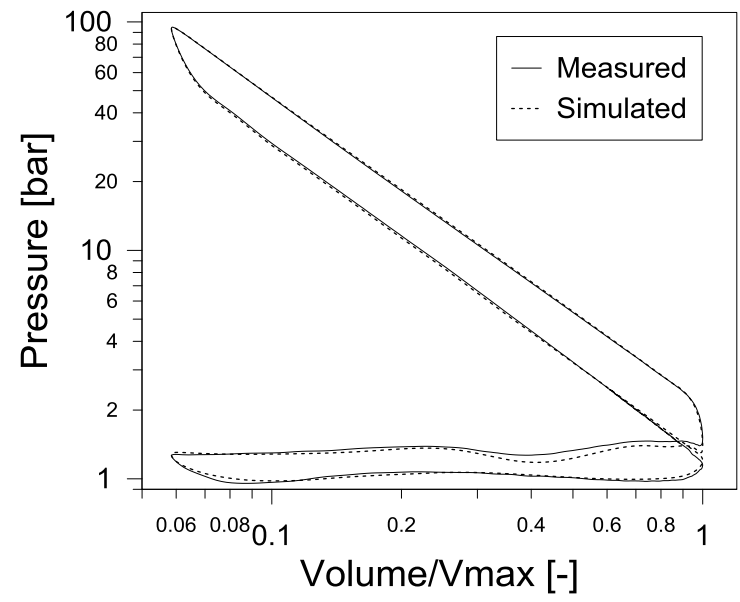

Figure 4. Comparison of experimental and simulated logarithm pressure versus logarithm volume profiles.

A further verification was performed aiming to evaluate the predictive capability to determine the temperature field for cylinder head and liner. The experimental thermocouple values were used to depict temperature maps that are compared to the simulated ones. The resulting graphs are presented in Figure 5. 

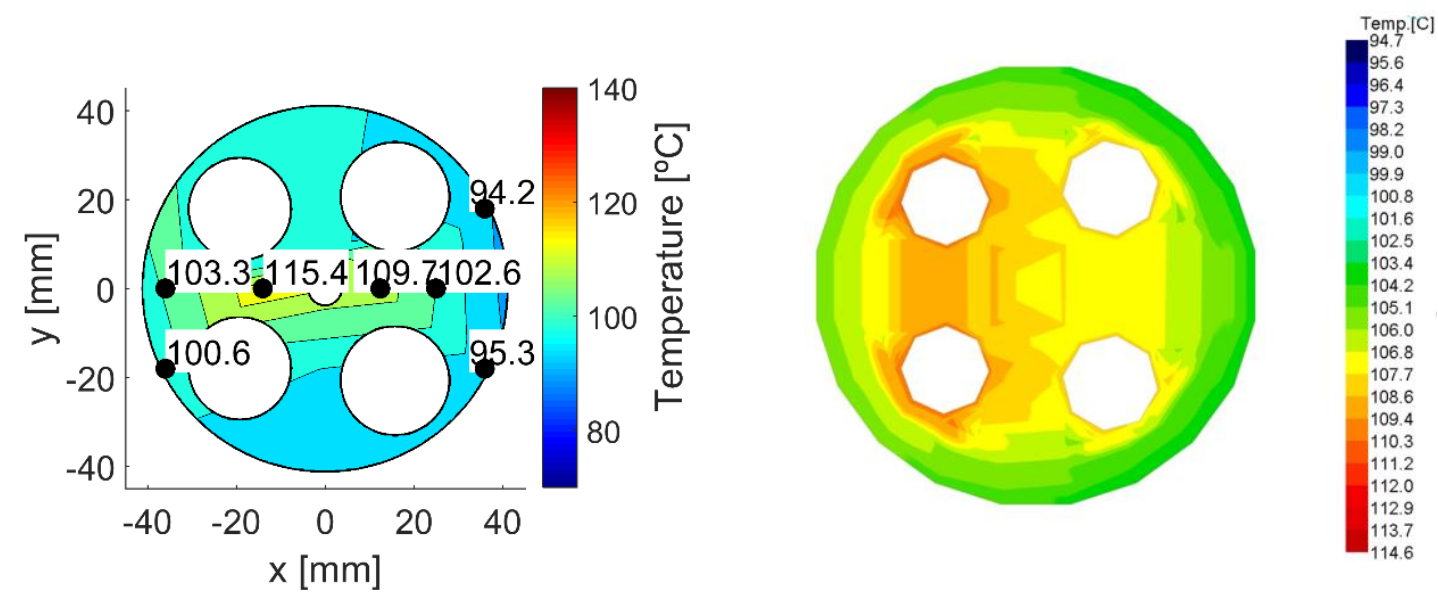

Figure 5. Comparison of experimental (left) and simulated (right) temperature maps at $4 \mathrm{~mm}$ from fire deck.

Table 5 quantifies the difference between the experimental and simulated temperatures for each one of the thermocouples. As it can be seen, the temperature differences range from $2.23 \%$ to $8.81 \%$, being more noticeable near to the outer limits (TC 35, 43, 31 and 19). This discrepancy is the result of a limitation of the model, since it is not possible to specify the coolant flow connecting the cylinder head to the liner. Furthermore, conditions as equivalence ratio distribution and injector locations cannot be defined in the current model. Finally, the mesh has a limited number of finite elements. Due to this, it is not possible to have the simulated value at the exact location of the thermocouple.

Despite of these discrepancies, the model is precise enough to allow prediction of the heat transfer values and trends that allow comparison of the $\mathrm{RCCl}$ performance in different conditions. In addition, the use of primary boundary conditions as pressure, mass and temperature together with experimental results allows to calibrate the model and compare their results versus the experimental temperature measurements.

Table 5. Comparison between measured and predicted temperature values for the different thermocouple positions at $4 \mathrm{~mm}$ from fire deck.

\begin{tabular}{|c|c|c|c|c|c|c|c|}
\hline Thermocouple number & 35 & 43 & 1 & 13 & 25 & 31 & 19 \\
\hline Experimental $\left[{ }^{\circ} \mathrm{C}\right]$ & 100.60 & 103.30 & 115.40 & 109.70 & 102.60 & 94.20 & 95.30 \\
\hline Simulated $\left[{ }^{\circ} \mathrm{C}\right]$ & 105.40 & 105.60 & 110.90 & 107.00 & 105.30 & 102.50 & 102.70 \\
\hline Percentage difference [\%] & 4.77 & 2.23 & 3.90 & 2.46 & 2.63 & 8.81 & 7.76 \\
\hline
\end{tabular}

\section{Results and discussion}

The results are divided into three subsections. First, the effects of several engine parameters on the diesel-gasoline RCCl heat transfer is explored by means of a series of parametric sweeps. Second, the RCCl heat transfer characteristics are explored for two different LRF, $98 \mathrm{ON}$ gasoline and E85, to compare their performance on the global energy path. Third, diesel-gasoline $\mathrm{RCCl}$ is compared versus $\mathrm{CDC}$ operation at a matched load condition to assess the main differences regarding the energy paths during the engine cycle. During the tests, the maximum PRR was limited to 10 bar/CAD to guarantee knock-free conditions. Otherwise, the stability of the thermal boundary layer 
could be compromised and the RCCl advantages in terms of heat transfer due to the low temperature combustion will be penalized.

\subsection{Influence of GF, EGR and diesel Sol on energy distribution}

\subsubsection{EGR sweep}

In order to evaluate the EGR effect on $\mathrm{RCCl}$ heat transfer, a parametric study was carried out for EGR levels of $0 \%, 20 \%$ and $40 \%$. All the other engine operating parameters (diesel Sol, injected fuel mass, engine speed, GF, intake temperature and intake pressure) were maintained constant. Fixed CA50 methodology was not applied here since normally that requires a different set of engine parameters for each operating condition. Table 6 details the settings used for the EGR sweep.

Table 6. Engine settings for the operating conditions tested in the EGR sweep.

\begin{tabular}{|l|c|c|c|}
\cline { 2 - 4 } \multicolumn{1}{c|}{} & EGR 0 \% & EGR 20 \% & EGR 40 \% \\
\hline Diesel Sol [CAD bTDC] & 60 & 60 & 60 \\
\hline IMEP [bar] & 3.47 & 3.91 & 3.58 \\
\hline Gasoline fraction [\%] & 60 & 60 & 60 \\
\hline Total fuel mass [mg/cycle] & 10.56 & 10.93 & 10.16 \\
\hline CA 50 [CAD bTDC] & 4.68 & 4.60 & 0.36 \\
\hline Intake temperature [ $\left.{ }^{\circ} \mathrm{C}\right]$ & 28 & 27.5 & 27 \\
\hline Intake pressure [bar] & 1.28 & 1.28 & 1.28 \\
\hline
\end{tabular}

From Table 6, it can be inferred that EGR levels higher than $20 \%$ slow down the combustion process, resulting in delayed CA50 values. This is explained due to the high amount of inert gas, which dilutes the air-fuel mixture and absorbs energy during the combustion process. Therefore, lower temperatures are expected, reducing the convective heat transfer to the engine walls. The analysis of Figure 6 allows to identify this phenomenon. The first two graphs do not present significant changes in the fire deck temperatures. This is expected, since both of them have similar combustion efficiency and CA50 values. Figure 7 presents the in-cylinder temperature (left), apparent heat release (left) and energy distribution (right). As it can be seen in Figure 7, the in-cylinder temperature and rate of heat release profiles are also similar for both cases. By contrast, using $40 \%$ EGR results in higher combustion duration, shifting the combustion phasing towards the expansion process i.e., at higher volumes. The impact of such phenomenon is the direct decrease of the maximum in-cylinder temperature, as illustrated in Figure 6 and 7.
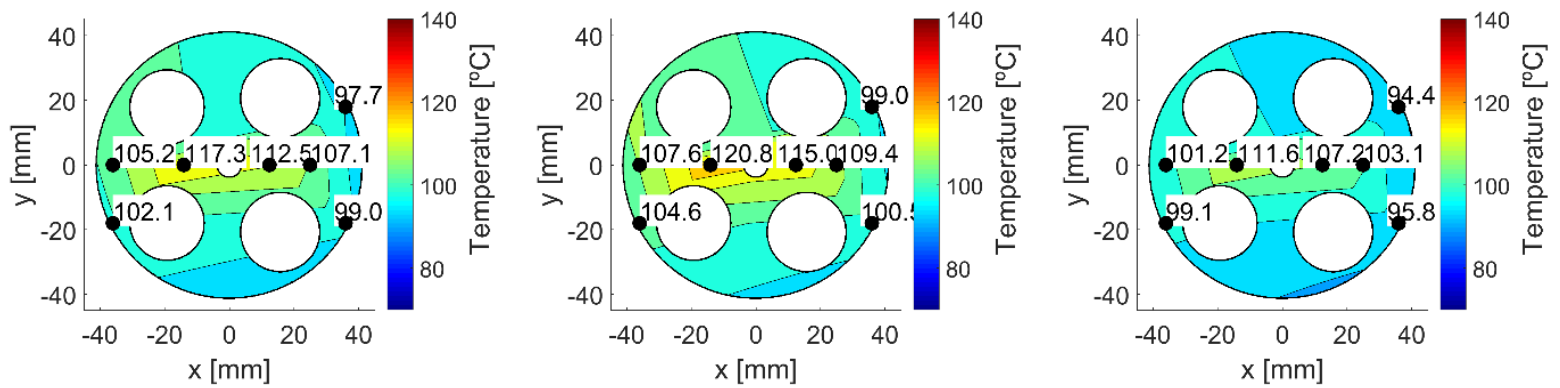

Figure 6. Measured cylinder head temperatures surfaces at $4 \mathrm{~mm}$ form firedeck for different EGR levels $(0,20$ and $40 \%)$. 
The analysis of Figure 7 also provides insights about the effect of EGR concentration on the heat release profiles and the energy paths. It can be noted a considerable increase in the heat release rate when the EGR is increased from $0 \%$ to $20 \%$. Nonetheless, such variation does not imply directly a temperature increase due to the higher mixture heat capacity for higher EGR levels. The different paths into which the energy is divided during the engine cycle can be seen in the bar chart of Figure 7. Both gross indicated efficiency (GIE) and exhaust losses do not present huge differences in the EGR sweep. However, lower combustion efficiencies are verified as the EGR rate increases. The lower temperature obtained during the combustion slows down the combustion process and enhances the quenching zones. Therefore, more fuel remains unburned and a lower quantity of energy is lost by heat transfer to the walls.
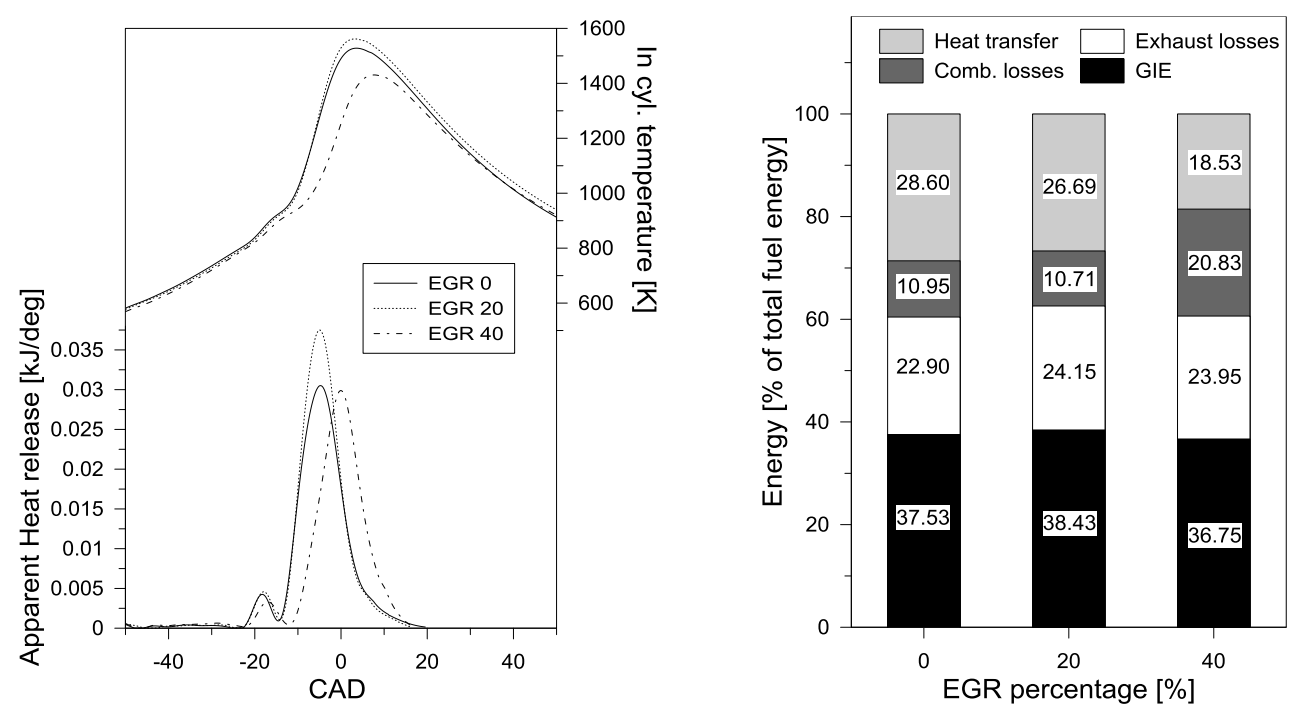

Figure 7. In cylinder temperature and apparent heat release (left) and energy distribution (right) for different $E G R$ levels (0, 20 and $40 \%)$

\subsubsection{Gasoline fraction sweep}

To assess the impact of the gasoline fraction ( $\left.G F=m_{\text {gasoline }} /\left(m_{\text {gasoline }}+m_{\text {diesel }}\right)\right)$ on the energy distribution, three different GF levels were tested $60 \%, 70 \%$ and $80 \%$. In this analysis, the diesel Sol values, EGR fraction, injected fuel mass, intake and exhaust pressures and temperatures were kept constant. Therefore, the differences in the combustion process can be only attributed to GF variations. Table 7 depicts the settings used during the tests as well as the CA50 values. As it can be seen, the CA50 tends to be more delayed as the GF increases due to lower portion of diesel fuel in the cylinder at the combustion onset.

Table 7. Engine settings for the operating conditions tested in the gasoline fraction sweep.

\begin{tabular}{|l|c|c|c|}
\cline { 2 - 4 } \multicolumn{1}{c|}{} & GF 60\% & GF 70\% & GF 80\% \\
\hline Diesel Sol [CAD bTDC] & 50 & 50 & 50 \\
\hline IMEP [bar] & 3.47 & 3.92 & 3.05 \\
\hline EGR [\%] & 0 & 0 & 0 \\
\hline Total fuel mass [mg/cycle] & 10.56 & 10.61 & 10.52 \\
\hline CA 50 [CAD bTDC] & 4.68 & 4.70 & 3.25 \\
\hline Intake temperature [ $\left.{ }^{\circ} \mathrm{C}\right]$ & 29.2 & 29.9 & 30 \\
\hline Intake pressure [bar] & 1.15 & 1.15 & 1.15 \\
\hline
\end{tabular}


The cylinder head temperature surfaces are depicted in Figure 8. As it can be seen, the increase in GF from $60 \%$ to $70 \%$ has not a direct impact on the temperature field. This is expected since the total fuel amount and the CA50 are similar. Nonetheless, the case with GF $80 \%$ presented a considerable decrease of the temperature values, with the maximum temperature being reduced in $8^{\circ} \mathrm{C}$. This could lead to a worse combustion process or improper phasing given by the high quantity of low reactivity fuel that can be forwarded to the piston gaps, or that is not burned due to the flame quenching near to walls.
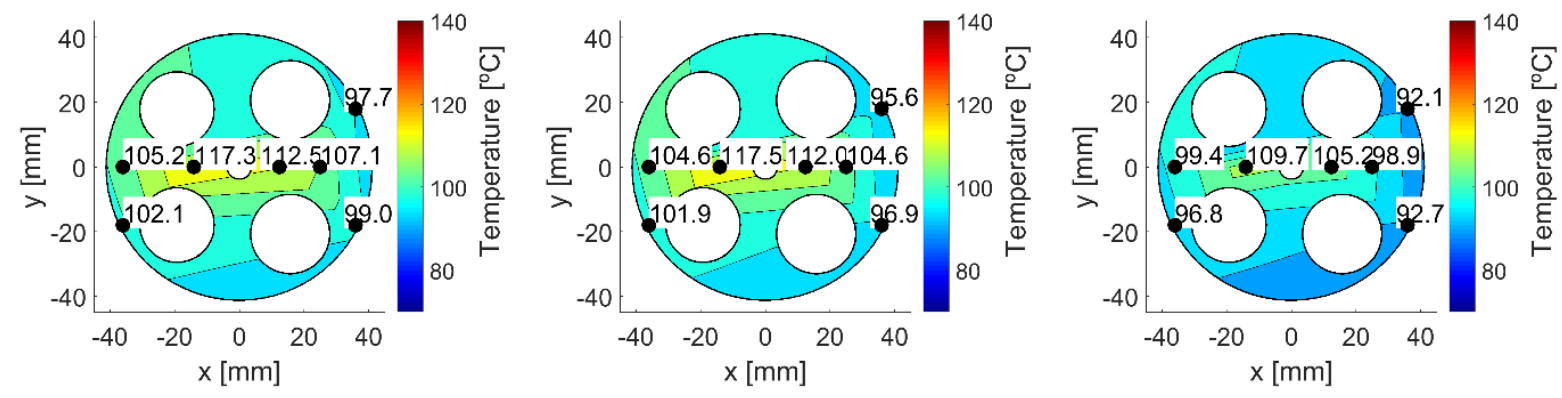

Figure 8. Measured cylinder head temperatures surfaces at $4 \mathrm{~mm}$ from firedeck for different GF quantities (60, 70 and $80 \%)$.

Figure 9 presents the in-cylinder temperature (left), apparent heat release (left) and energy distribution (right). It can be inferred that the increase in GF from $60 \%$ to $70 \%$ slightly improves the combustion process, releasing higher energy fraction closer to the TDC. This can be also realized at the temperature profiles. These effects will help to achieve a proper fuel conversion efficiency, as seen at the energy bars. Nonetheless, the increase in GF to $80 \%$ have no apparent benefits. The decrease in diesel quantity delays the combustion process, resulting in larger combustion durations and lower temperature values. In addition, the higher amount of gasoline mass injected at the intake port has several issues as impingement at the pipe walls and the forwarding of fuel to the piston gaps during the compression stroke, reducing the combustion efficiency. The energy bar chart at Figure 9 (right) confirms this statement.

In terms of exhaust losses, the bars of GF $60 \%$ and GF $70 \%$ are similar. However, the GIE value for GF $70 \%$ is slightly higher due to the lower combustion losses and heat transfer losses. In the case of GF $80 \%$ the GIE is penalized due to the low combustion efficiency, which is consequence of the low in-cylinder temperature and large combustion duration. Despite of presenting lower heat transfer and exhaust losses, its GIE value still remains lower than the other ones. Therefore, it can be concluded that for conditions at low load, high amounts of gasoline can result in excessive combustion inefficiencies decreasing the final GIE value. 

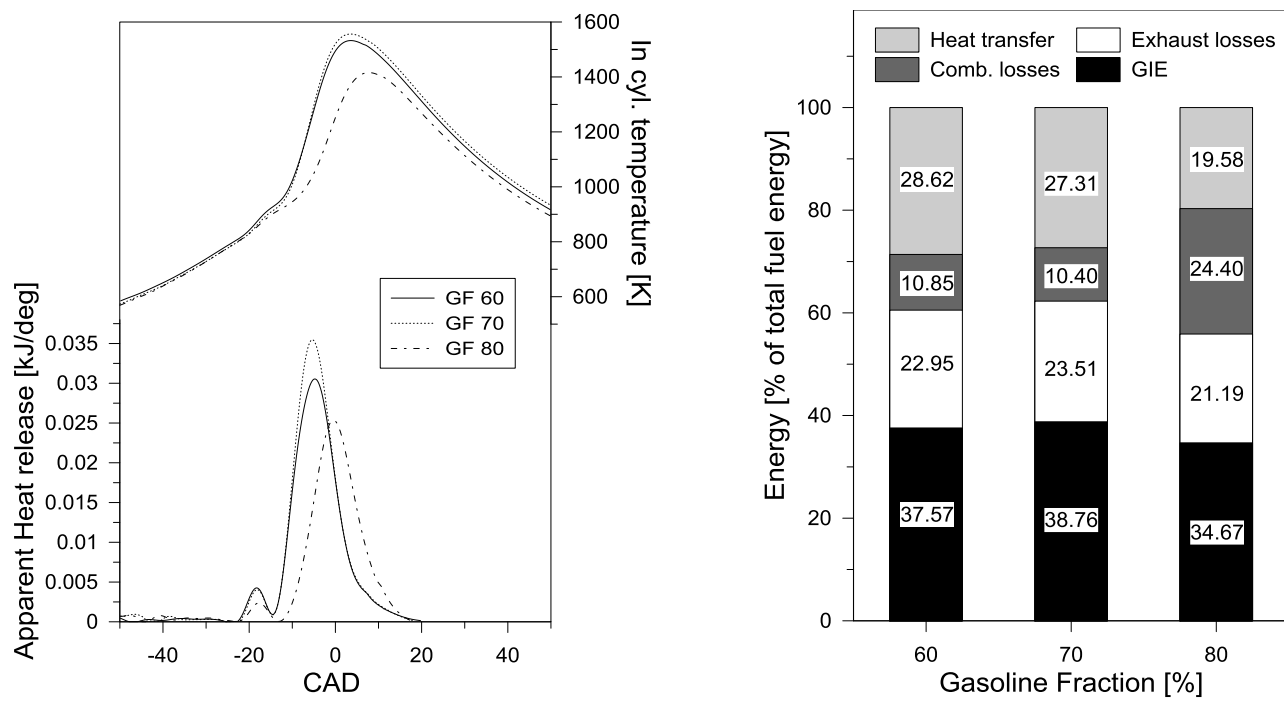

Figure 9. In cylinder temperature and apparent heat release (left) and energy distribution (right) for different gasoline fraction values $(60,70$ and $80 \%)$

\subsubsection{Diesel Sol sweep}

The last sweep performed addresses different start of injection timings for the diesel fuel. To isolate its effect on the combustion process, only the diesel Sol values were changed during the tests. Table 8 summarizes the settings used during the tests as well as the CA50 values that were obtained for each operating condition. As it can be seen, the CA50 delays as the Sol is moved towards the BDC. In spite of this, the IMEP values are similar for all the cases, indicating that the cycle efficiency is kept almost constant independently on the diesel Sol.

Table 8. Engine settings for the operating conditions tested in the diesel Sol sweep.

\begin{tabular}{|l|c|c|c|c|}
\cline { 2 - 5 } \multicolumn{1}{c|}{} & Sol 30 & Sol 40 & Sol 50 & Sol 60 \\
\hline EGR [\%] & 40 & 40 & 40 & 40 \\
\hline IMEP [bar] & 3.95 & 3.95 & 4.08 & 3.89 \\
\hline Gasoline fraction [\%] & 70 & 70 & 70 & 70 \\
\hline Total fuel mass [mg/cycle] & 10.61 & 10.60 & 10.45 & 10.58 \\
\hline CA 50 [CAD bTDC] & 6.02 & 4.25 & 0.68 & 0.66 \\
\hline Intake temperature [ ${ }^{\circ} \mathrm{C}$ ] & 32.4 & 32.3 & 32 & 31.9 \\
\hline Intake pressure [bar] & 1.14 & 1.14 & 1.14 & 1.14 \\
\hline
\end{tabular}

As shown in Figure 10, the temperature measurements for the cylinder head present a low level of dependence on the Sol. Maximum temperature differences are below $2^{\circ} \mathrm{C}$ for the thermocouple 43. Therefore, it is expected that the total energy losses will be only dependent on the combustion duration, since the gas temperature and the cylinder head temperature are similar for all the cases. Figure 11 demonstrates that the temperature peak values are similar for all the cases. However, as the diesel Sol is delayed, a diffusive characteristic heat release profile is obtained, with a first peak from the premixed phase and a second one from the diffusive phase. In this way, the higher temperatures obtained during the premixed phase are maintained by the diffusive combustion. Therefore, the heat transfer process is enhanced, reaching higher total losses during the cycle as can be verified in Figure 11 (right). 

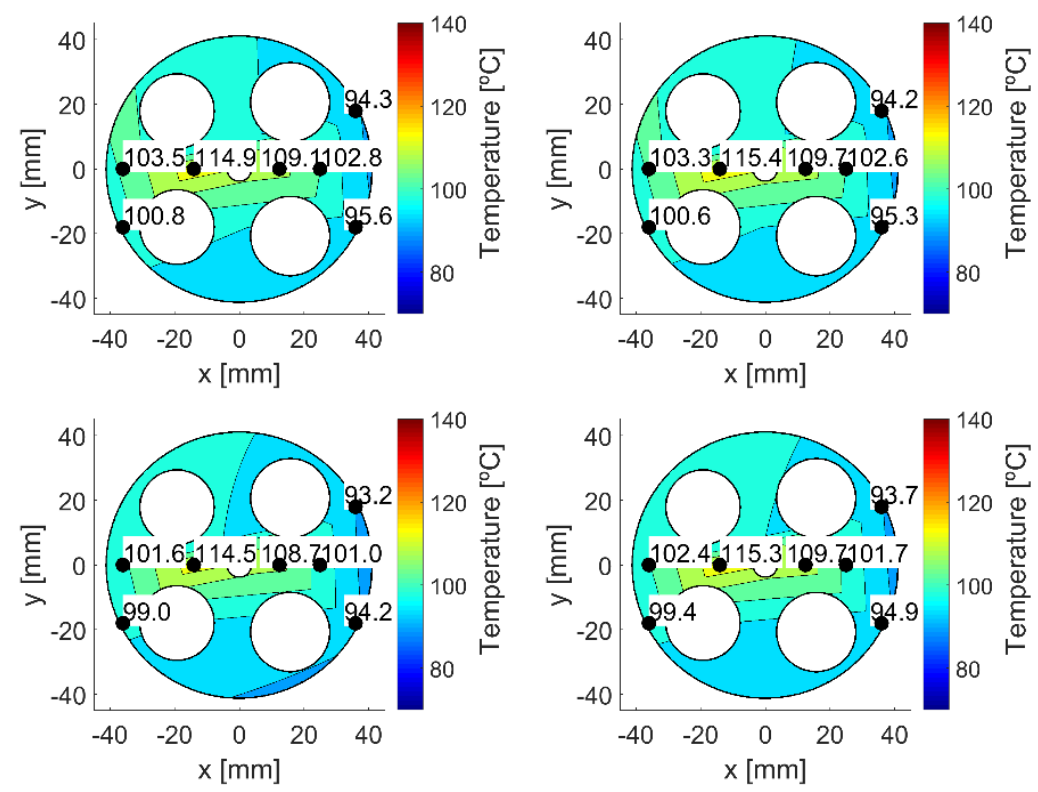

Figure 10. Measured cylinder head temperatures surfaces at $4 \mathrm{~mm}$ from firedeck for different Start of Injection values (30, 40, 50 and 60 CAD bTDC).

As shown in Figure 11 (right), despite the lower heat transfer losses for some operating conditions, the final GIE is nearly constant. The reason for this behavior relies on the higher combustion inefficiencies from the cases with diesel Sol 40 to 60 CAD bTDC since the diffusive phase is not presented. Nonetheless, as the Sol is advanced, the total heat transfer decreases. Therefore, it should exist a balance between these effects. Indeed, a trade-off is verified for the case with Sol 50 CAD bTDC, which presents considerable high combustion efficiency in conjunction with lower heat transfer losses.
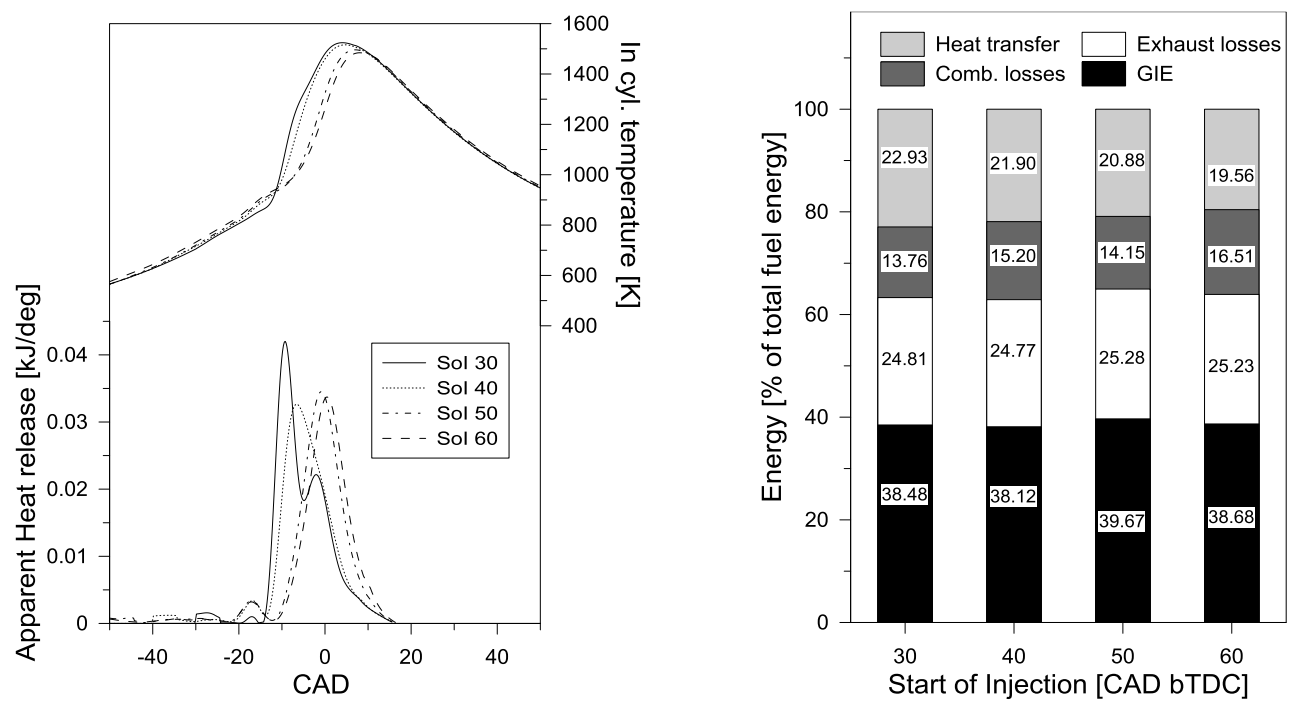

Figure 11. In cylinder temperature and apparent heat release (left) and energy distribution (right) for different start of injection values $(30,40,50$ and 60 CAD bTDC). 


\subsection{E85 versus Gasoline}

Recent studies investigated the use of E85 as LRF fuel for $\mathrm{RCCl}$, reporting better or worse indicated efficiencies than using gasoline fuel depending on the operating conditions [48]. In order to understand the main reasons for this difference, a comparison of the energy usage with both fuels at a matched load and CA50 condition is performed in this subsection. The engine settings of the operating conditions under comparison are summarized in Table 9. As it can be seen, the EGR quantity and energy from the LRF are almost equal for both conditions. Only the diesel Sol in the case of E85 is slightly advanced to compensate for the fuel reactivity differences and maintain the CA50.

Table 9. Engine settings for the operating conditions tested to compare diesel-gasoline and diesel-E85 operation.

\begin{tabular}{|l|c|c|}
\cline { 2 - 3 } \multicolumn{1}{c|}{} & Diesel-E85 & Diesel-Gasoline \\
\hline EGR [\%] & 40 & 40 \\
\hline Diesel Sol [CAD bTDC] & 36 & 40 \\
\hline PER [\%] & 70 & 69 \\
\hline IMEP [bar] & 8.1 & 7.9 \\
\hline CA50 [CAD aTDC] & 7.84 & 7.73 \\
\hline
\end{tabular}

The temperature maps from the experimental measurements are depicted in Figure 12 for both cylinder head (at $4 \mathrm{~mm}$ and $7 \mathrm{~mm}$ from fire deck) and liner. In general terms, the temperature difference for the two fuels range from $4^{\circ} \mathrm{C}$ to $6^{\circ} \mathrm{C}$, the gasoline values being higher than those of E85. From the temperature and apparent heat release profiles depicted in Figure 13, it can be inferred that the main reason for these differences is explained by the combustion process development. The gasoline heat release has higher peak values than E85. Therefore, the temperature increases in a similar proportion. Nonetheless, the end of combustion for E85 is located further from TDC than with the gasoline, which increases the heat losses at the end of the combustion period. 

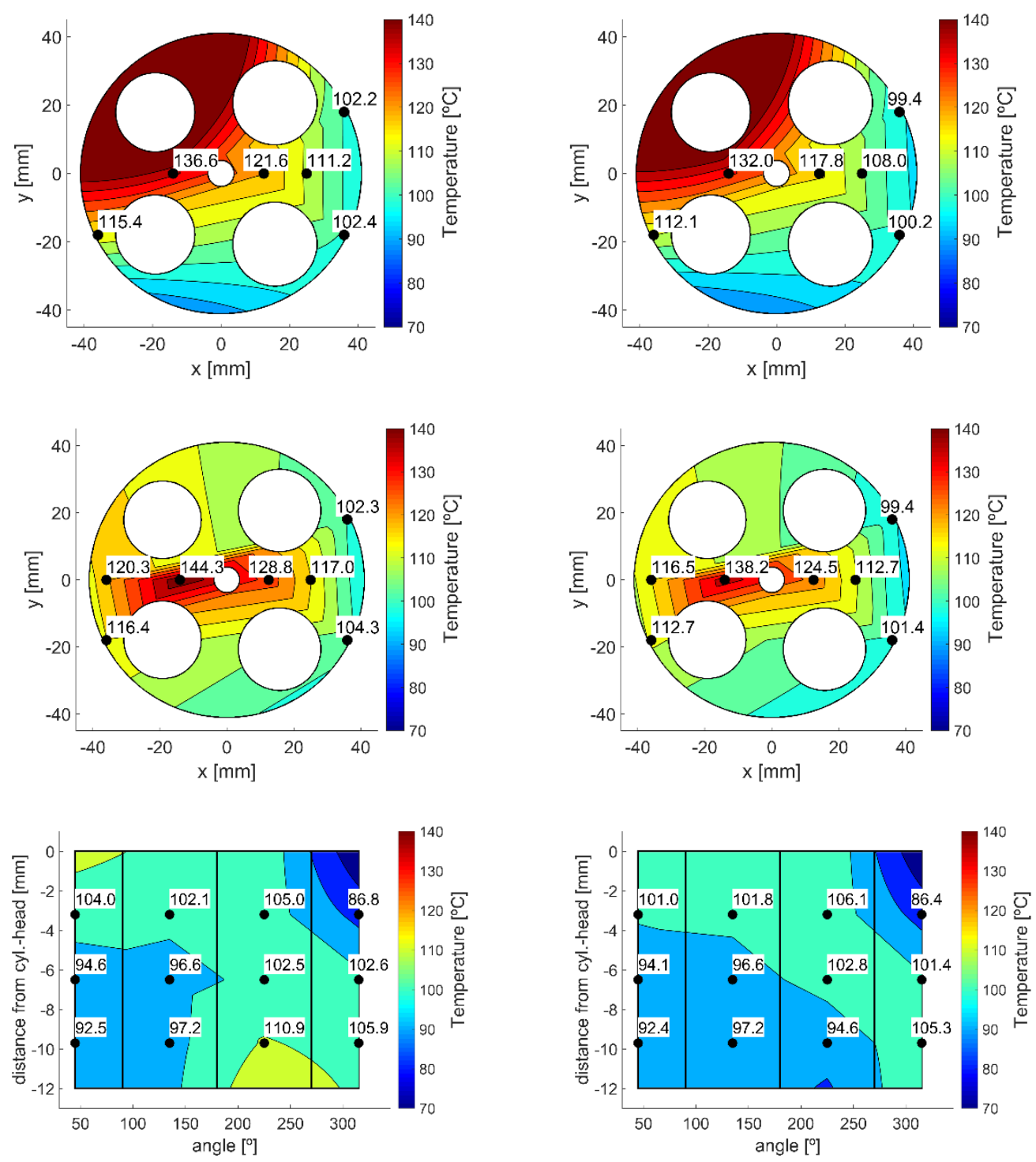

Figure 12. Measured cylinder head temperatures surfaces at $7 \mathrm{~mm}$ (upper graphs) and $4 \mathrm{~mm}$ (middle graphs) from firedeck and liner (lower graphs) temperatures for RCCl-gasoline (left) and CDC (right).

As shown in Figure 13, the total heat transfer losses for both fuels are similar, with an absolute difference lower than $1 \%$ as can be seen in the energy bars. However, the exhaust gas temperature for E85 is higher since the combustion process takes place during a wider period. This results in higher losses by the exhaust gases. Even with the higher combustion efficiency for this fuel, the GIE values are still under those from gasoline. Nonetheless, the similar performance of E85 regarding the energy paths proves that this fuel can be a surrogate for $\mathrm{RCCl}$ operation having the advantage of extending the operation limit of RCCI [48]. 

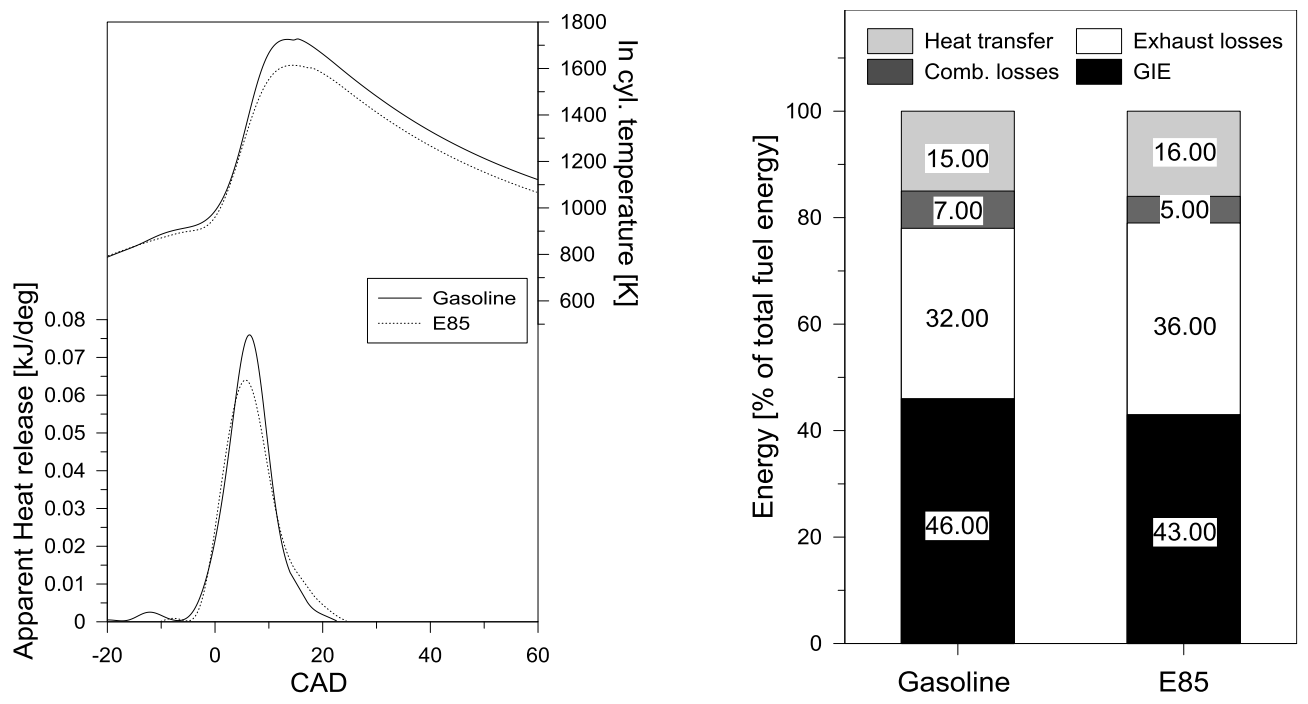

Figure 13. In cylinder temperature and apparent heat release (left) and energy distribution (right) for Gasoline and E-85.

\section{3. $\mathrm{RCCl}$ versus $\mathrm{CDC}$ at matched load conditions}

In this subsection, the $\mathrm{RCCl}$ combustion is compared to a CDC condition. The main parameters of the operating conditions used to compare these combustion modes are given in Table 10.

Table 10. Engine settings for the operating conditions tested to compare RCCI-Gasoline and conventional diesel operation.

\begin{tabular}{|l|c|c|}
\cline { 2 - 3 } \multicolumn{1}{c|}{} & RCCI-Gasoline & CDC \\
\hline EGR [\%] & 40 & 0 \\
\hline Diesel Sol [CAD bTDC] & 50 & 40 \\
\hline GF [\%] & 85 & 0 \\
\hline IMEP [bar] & 7.02 & 6.95 \\
\hline CA50 [CAD aTDC] & 2.25 & 14 \\
\hline
\end{tabular}

The temperature maps from the experimental measurements at the cylinder head and liner are depicted in Figure 14. Both maps show lower temperature values for the RCCI case. This feature results in lower energy transfer to the coolant fluid and decreases the thermal solicitation of these components. 

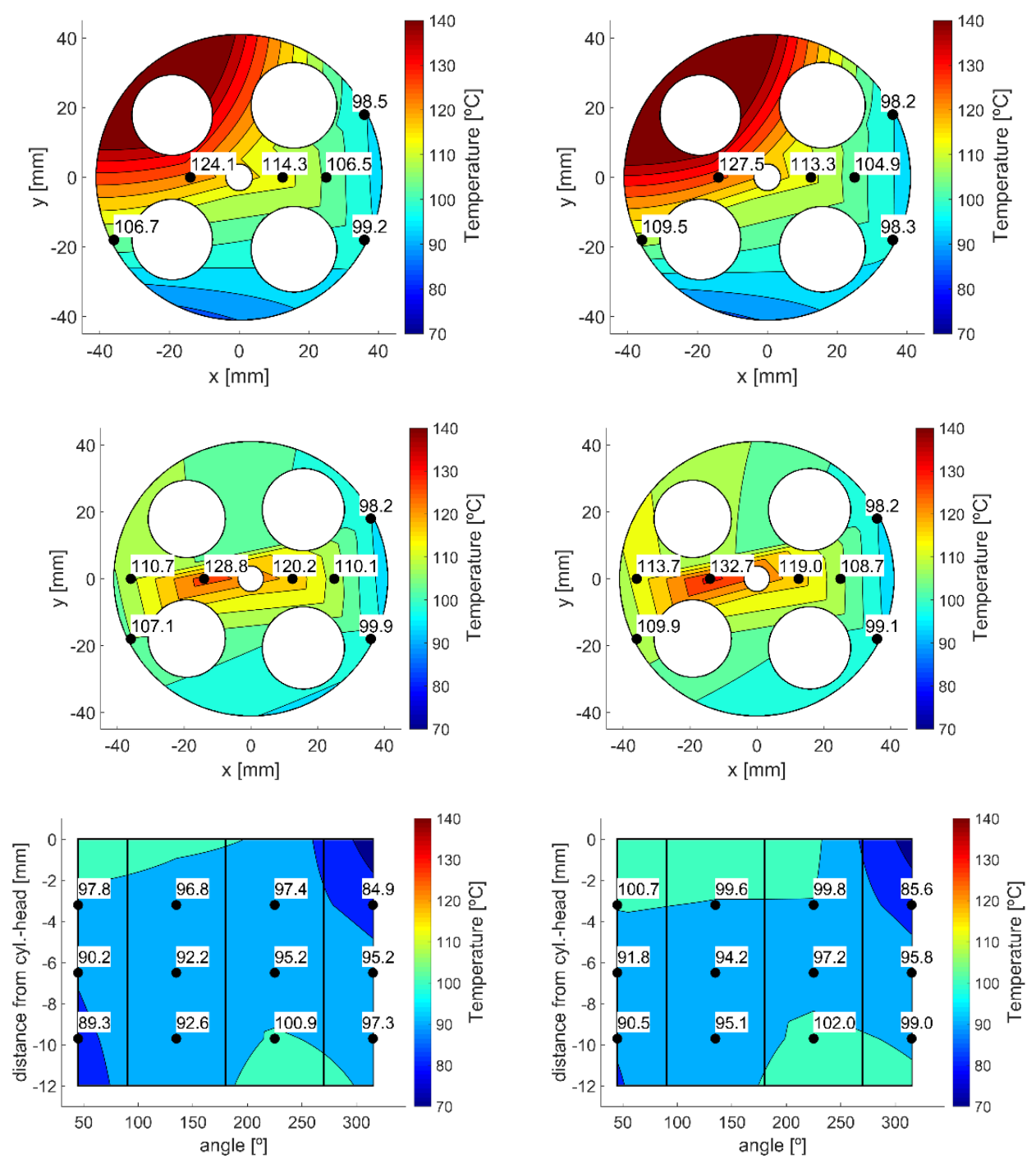

Figure 14. Measured cylinder head temperatures surfaces at $7 \mathrm{~mm}$ (upper graphs) and $4 \mathrm{~mm}$ (middle graphs) from firedeck and liner (lower graphs) temperatures for RCCl-gasoline (left) and CDC (right).

Figure 15 shows the in-cylinder temperature profiles (left), apparent heat release (left) and the energy distribution (right) for $\mathrm{RCCl}$ and $\mathrm{CDC}$. An oscillation is verified at the beginning of the heat release profile for the CDC case which can be attributed to the heat absorption during the fuel vaporization inside the combustion chamber. It can be noted that the temperature peak obtained during the $\mathrm{RCCl}$ is considerable higher than CDC, as previously mentioned. This can be attributed to the higher amount of energy released in a short period of time. However, at the end of combustion, the temperature experiences a steep fall, reducing its levels under $1200 \mathrm{~K}$. Therefore, the temperature gradients that are the driving potential to heat transfer are also decreased, resulting in a more efficient cycle. Regarding CDC temperature, the peak value is lower than RCCI. However, as the diffusive combustion proceeds, the temperature is maintained for a longer period of time, increasing the time available for heat transfer. This can be also confirmed at the energy distribution bars, where the heat transfer losses in CDC combustion are $13 \%$ higher than $\mathrm{RCCl}$ for the condition compared here. As confirmed in Figure 15 (left), the globally lean operation in CDC reduces bulk gas temperature, but the highly stratified nature of the combustion event introduces strong thermal gradients and high temperatures with both occurring in close proximity to the combustion 
chamber surfaces. By contrast, in dilute highly premixed strategies, like RCCl, the peak bulk gas temperatures are higher, but the increase in charge uniformity shifts the global and local combustion temperatures to be more similar, removing localized effects and reducing the driving potential for in-cylinder heat transfer losses. In addition, the short combustion duration result in higher temperatures for a reduced period, whilst in the CDC case, the diffusive part of the combustion maintains the temperature levels obtained during the premixed phase for a longer time. Therefore, it is expected that the surface temperature should be lower for the $\mathrm{RCCl}$ case due to this short combustion and the reduced heat transfer.

From Figure 15, it can be noted that the diesel temperature values at 80 CAD aTDC are $\approx 200 \mathrm{~K}$ higher than RCCl. This leads to higher energy loss by exhaust gases due to the higher enthalpy that is not used for generate work during the engine cycle. By contrast, the values of combustion inefficiency are much lower for CDC, presenting a total decrease of $75 \%$. Nonetheless, this improvement is not enough to overcome the higher losses from heat transfer and exhaust gases. For these reasons, the final value of GIE for $\mathrm{RCCl}$ is higher than CDC.
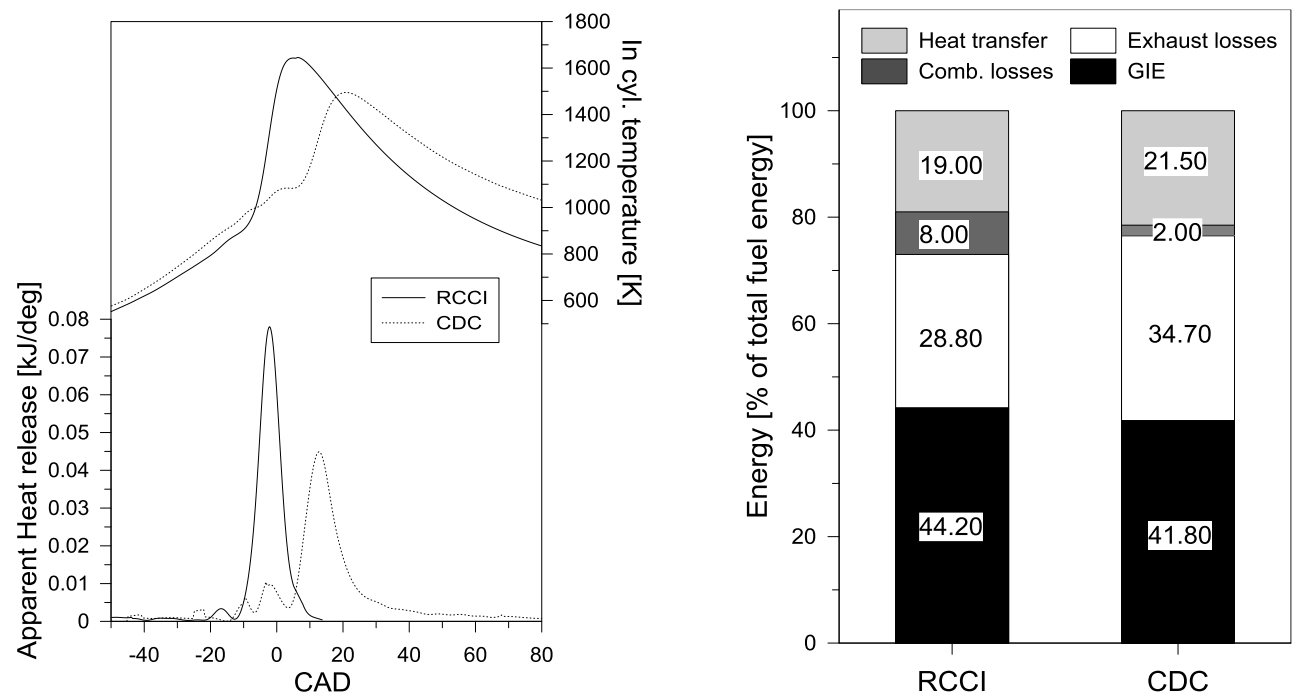

Figure 15. In cylinder temperature and apparent heat release (left) and energy distribution (right) for $\mathrm{RCCl}$-gasoline and CDC.

\section{Conclusions}

This work evaluated the energy balance in a $\mathrm{RCCl}$ engine for different fuels by experimental measurements. In addition, a GT power model was developed to allow the calculation of heat transfer quantities. The conditions investigated addressed different EGR, GF and Sol values. Furthermore, it was performed a comparison between gasoline and E85 at matched conditions. Finally, a quantitative analysis was performed for a similar condition of $\mathrm{RCCl}$ and conventional diesel combustion aiming to assess the major advantages for $\mathrm{RCCl}$ over $\mathrm{CDC}$ with regards the energy losses.

From the first study, it could be concluded that both EGR and GF play a fundamental role on combustion efficiency. Increasing the EGR percentage to values higher than $20 \%$ and GF to values higher than $70 \%$ demonstrated to worsen the combustion process, resulting in huge amounts of $\mathrm{HC}$ and $\mathrm{CO}$ at the engine exhaust gases. Consequently, the energy that could be provided by this fuel is not used, reducing the global efficiency of 
the engine. The diesel Sol sweep provided insight regarding its effects on the heat losses. It could be concluded that even changing the diesel Sol values form 30 to 60 CAD bTDC, the heat losses remained unaltered.

The comparison between diesel-gasoline and diesel-E85 revealed that the heat transfer quantities as well as the GIE values are similar for both fuels. The exhaust losses are slightly higher for the E85 as a result of the higher combustion duration. Nonetheless, this effect was balanced by higher combustion efficiency value allowing to conclude that both low reactivity fuels can be applied in $\mathrm{RCCl}$ combustion giving similar results in terms of energy usage.

Finally, the comparison of diesel-gasoline RCCI versus CDC demonstrated the superior capacity of $\mathrm{RCCl}$ in exploiting the energy released from the fuel combustion. The short combustion duration compared to CDC resulted in a reduction of $13 \%$ in the heat transfer values. Moreover, the low enthalpy of the exhaust gas with RCCI leads to lower exhaust losses than CDC. Nonetheless, the combustion efficiency values are still low compared to the $\mathrm{CDC}$ and the improvement of this parameter is still a challenge in $\mathrm{RCCl}$ combustion.

\section{Acknowledgments}

The authors gratefully acknowledge General Motors Global Research \& Development for providing the engine used in this investigation. The authors also acknowledge FEDER and Spanish Ministerio de Economía y Competitividad for partially supporting this research through TRANCO project (TRA2017-87694-R).

\section{References}

[1] Araghi Y, Kroesen M, Van Wee B. Identifying reasons for historic car ownership and use and policy implications: An explorative latent class analysis. Transport Policy, Volume 56, 2017, Pages 12-18.

[2] González J, Otsuka Y, Araki M, Shiga S. Impact of new vehicle market composition on the light-duty vehicle fleet $\mathrm{CO} 2$ emissions and cost. Energy Procedia, Volume 105, 2017, Pages 3862-3867.

[3] Singh S, Kennedy C. Estimating future energy use and CO2 emissions of the world's cities. Environmental Pollution, Volume 203, 2015, Pages 271-278.

[4] Commission Regulation (EC) No 692/2008 of 18 July 2008 implementing and amending Regulation (EC) No 715/2007 of the European Parliament and of the Council on type-approval of motor vehicles with respect to emissions from light passenger and commercial vehicles (Euro 5 and Euro 6) and on access to vehicle repair and maintenance information. Off. J. Eur. Union L199, 1-136. European Commission, 2008.

[5] Oliveira M, Silva C, Moreno-Tost R, Farias T, Rodríguez-Castellón E. Modelling of NOx emission factors from heavy and light-duty vehicles equipped with advanced aftertreatment systems. Energy Conversion and Management, Volume 52, Issues 8 9, 2011, Pages 2945-2951.

[6] Posada F, Chambliss S, Blumberg K. Costs of emission reduction technologies for heavy-duty diesel vehicles. ICCT White paper 2016. 
[7] Jiaqiang E, Zuo W, Gao J, Peng Q, Zhang Z, Hieu P. Effect analysis on pressure drop of the continuous regeneration-diesel particulate filter based on $\mathrm{NO} 2$ assisted regeneration. Applied Thermal Engineering, Volume 100, 2016, Pages 356-366.

[8] Garcia A, Monsalve-Serrano J, Heuser B, Jakob M, Kremer F, Pischinger S. Influence of fuel properties on fundamental spray characteristics and soot emissions using different tailor-made fuels from biomass. Energy Conversion and Management, Volume 108, 2016, Pages 243-254.

[9] Wu H, Wang R, Ou D, Chen Y, Chen T. Reduction of smoke and nitrogen oxides of a partial $\mathrm{HCCl}$ engine using premixed gasoline and ethanol with air. Applied Energy, Volume 88, Issue 11, 2011, Pages 3882-3890.

[10] Harada A, Shimazaki N, Sasaki S. The effects of mixture formation on premixed lean diesel combustion. SAE Tech Pap 1998, 980533.

[11] García-Valladolid P, Tunestal P, Monsalve-Serrano J, García A, Hyvönen J. Impact of diesel pilot distribution on the ignition process of a dual fuel medium speed marine engine. Energy Conversion and Management, Volume 149, 2017, Pages 192205.

[12] Koci C, Ra Y, Krieger R, Andrie M, Foster D, Siewert R, Durrett R, Isaac Ekoto, Miles $P$. Detailed Unburned Hydrocarbon Investigations in a Highly-Dilute Diesel Low Temperature Combustion Regime. SAE Int. J. Engines 2(1):858-879, 2009, doi:10.4271/2009-01-0928.

[13] Yao M, Zheng Z, Liu H. Progress and recent trends in homogeneous charge compression ignition $(\mathrm{HCCl})$ engines. Progress in Energy and Combustion Science, Volume 35, Issue 5, 2009, Pages 398-437.

[14] Singh A, Agarwal A. Combustion characteristics of diesel $\mathrm{HCCl}$ engine: an experimental investigation using external mixture formation technique. Appl Energy 2012, 99, 116-25.

[15] Maurya R, Agarwal A. Experimental investigation on the effect of intake air temperature and air-fuel ratio on cycle-to-cycle variations of $\mathrm{HCCl}$ combustion and performance parameters. Appl Energy 2011, 88, 1153-63.

[16] Saxena S, Bedoya I. Fundamental phenomena affecting low temperature combustion and $\mathrm{HCCl}$ engines, high load limits and strategies for extending these limits. Progress in Energy and Combustion Science, Volume 39, Issue 5, 2013, Pages 457-488.

[17] Komninos N. Assessing the effect of mass transfer on the formation of $\mathrm{HC}$ and $\mathrm{CO}$ emissions in $\mathrm{HCCl}$ engines, using a multi-zone model. Energy Conversion and Management, Volume 50, Issue 5, 2009, Pages 1192-1201.

[18] Xiangyu Zhang, Hu Wang, Zunqing Zheng, Rolf Reitz, Mingfa Yao, Experimental investigations of gasoline partially premixed combustion with an exhaust rebreathing valve strategy at low loads, Applied Thermal Engineering, Volume 103, 2016, Pages 832-841.

[19] Das P, Subbarao P, Subrahmanyam J. Effect of main injection timing for controlling the combustion phasing of a homogeneous charge compression ignition engine using a new dual injection strategy. Energy Conversion and Management, Volume 95, 2015, Pages 248-258.

[20] Yang Y, Dec J, Dronniou N, Sjöberg M. Tailoring $\mathrm{HCCl}$ heat-release rates with partial fuel stratification: Comparison of two-stage and single-stage-ignition fuels. Proceedings of the Combustion Institute, Volume 33 (2), pp. 3047-3055, 2011. 
[21] Bendu $\mathrm{H}$, Murugan S. Homogeneous charge compression ignition ( $\mathrm{HCCl}$ ) combustion: Mixture preparation and control strategies in diesel engines. Renewable and Sustainable Energy Reviews, Volume 38, October 2014, Pages 732746.

[22] Bessonette P, Schleyer C, Duffy K, Hardy W, Liechty M. Effects of fuel property changes on heavy-duty HCCl combustion. SAE paper 2007-01-0191, 2007.

[23] Inagaki K, Fuyuto T, Nishikawa K, Nakakita K, Sakata I. "Dual-Fuel PCI Combustion Controlled by In-Cylinder Stratification of Ignitability," SAE Technical Paper 2006-010028, 2006.

[24] Manente V, Tunestal P, Johansson B et al." Effects of Ethanol and Different Type of Gasoline Fuels on Partially Premixed Combustion from Low to High Load," SAE Technical Paper 2010-01-0871, 2010.

[25] Kalghatgi GT. Auto-ignition quality of practical fuels and implications for fuel requirements of future SI and $\mathrm{HCCl}$ engines. SAE paper 2005-01-0239, 2005.

[26] Benajes J, Molina S, García A, Monsalve-Serrano J, Durrett R. Conceptual model description of the double injection strategy applied to the gasoline partially premixed compression ignition combustion concept with spark assistance. Applied Energy, Volume 129, 2014, Pages 1-9.

[27] Benajes J, Molina S, García A, Monsalve-Serrano J, Durrett R. Performance and engine-out emissions evaluation of the double injection strategy applied to the gasoline partially premixed compression ignition spark assisted combustion concept. Applied Energy, Volume 134, 2014, Pages 90-101.

[28] Kokjohn S L, Hanson R M, Splitter D A, Reitz R D. Fuel reactivity controlled compression ignition (RCCl): a pathway to controlled high-efficiency clean combustion, International Journal of Engine Research, 2011. Volume 12, 2011, Pages 209-226.

[29] Molina S, García A, Monsalve-Serrano J, Estepa D. Miller cycle for improved efficiency, load range and emissions in a heavy-duty engine running under reactivity controlled compression ignition combustion. Applied Thermal Engineering, Volume 136, 2018, Pages 161-168.

[30] Benajes J, García A, Monsalve-Serrano J, Boronat V. Gaseous emissions and particle size distribution of dual-mode dual-fuel diesel-gasoline concept from low to full load. Applied Thermal Engineering, Volume 120, 2017, Pages 138-149.

[31] Li Y, Jia M, Chang Y, Xie M, Reitz R. Towards a comprehensive understanding of the influence of fuel properties on the combustion characteristics of a $\mathrm{RCCl}$ (reactivity controlled compression ignition) engine. Energy, Volume 99, 2016, Pages 69-82.

[32] Benajes J, García A, Monsalve-Serrano J, Balloul I, Pradel G. Evaluating the reactivity controlled compression ignition operating range limits in a highcompression ratio medium-duty diesel engine fueled with biodiesel and ethanol. International Journal of Engine Research, Volume 18 (1-2), Pages 66-80, 2017.

[33] Qian Y, Ouyang L, Wang X, Zhu L, Lu X. Experimental studies on combustion and emissions of RCCl fueled with n-heptane/alcohols fuels. Fuel, Volume 162, 2015, Pages 239-250.

[34] Benajes J, García A, Monsalve-Serrano J, Boronat V. Dual-Fuel Combustion for Future Clean and Efficient Compression Ignition Engines. Applied Sciences 7(1):36, 2017. 
[35] Zhou D, Yang W, An H, Li J. Application of CFD-chemical kinetics approach in detecting $\mathrm{RCCl}$ engine knocking fuelled with biodiesel/methanol. Applied Energy, Volume 145, 2015, Pages 255-264

[36] García A, Monsalve-Serrano J, Rückert Roso V, Santos Martins M. Evaluating the emissions and performance of two dual-mode RCCl combustion strategies under the World Harmonized Vehicle Cycle (WHVC). Energy Conversion and Management, Volume 149, 2017, Pages 263-274.

[37] Benajes J, García A, Monsalve-Serrano J, Boronat V. An investigation on the particulate number and size distributions over the whole engine map from an optimized combustion strategy combining RCCl and dual-fuel diesel-gasoline. Energy Conversion and Management, Volume 140, 2017, Pages 98-108.

[38] Wang Y, Yao M, Li T, Zhang W, Zheng Z. A parametric study for enabling reactivity controlled compression ignition $(\mathrm{RCCl})$ operation in diesel engines at various engine loads. Applied Energy, Volume 175, 2016, Pages 389-402.

[39] Splitter D, Wissink M, Hendricks T, Ghandhi J, Reitz R. Comparison of RCCl, $\mathrm{HCCl}$, and CDC operation from low to full load. THIESEL 2012 conference on thermo-and fluid dynamic processes in direct injection engines.

[40] Li Y, Jia M, Chang Y, Xu Z, Xu G, Liu H, Wang T. Principle of determining the optimal operating parameters based on fuel properties and initial conditions for RCCl engines.Fuel, Volume 216, 2018, Pages 284-295.

[41] Benajes J, García A, Pastor JM, Monsalve-Serrano J, Effects of piston bowl geometry on Reactivity Controlled Compression Ignition heat transfer and combustion losses at different engine loads. Energy, Volume 98, 2016, Pages 64-77.

[42] Solouk A, Tripp J, Shakiba-Herfeh M, Shahbakhti M. Fuel consumption assessment of a multi-mode low temperature combustion engine as range extender for an electric vehicle. Energy Conversion and Management, Volume 148, 2017, Pages 1478-1496

[43] Olmeda P, Martin J, Garcia A, Villalta D, Warey A, Domenech V. A Combination of Swirl Ratio and Injection Strategy to Increase Engine Efficiency. SAE International Journal of Engines 10(3):2017, doi:10.4271/2017-01-0722.

[44] Agarwal A, Pandey A, Gupta A, Aggarwal S, Kushari A. Novel combustion concepts for sustainable energy development. Springer. ISBN 978-81-322-2211-8.

[45] Gamma Technologies: Engine performance manual. 2018.

[46] Li Y, Jia M, Chang Y, Kokjohn S, Reitz R. Thermodynamic energy and exergy analysis of three different engine combustion regimes. Applied Energy, Volume 180, 2016, Pages 849-858.

[47] Morel T, Keribar R. A Model for Predicting Spatially and Time Resolved Convective Heat Transfer in Bowl-in-Piston Combustion Chambers. SAE Technical papers, 1985, doi: 10.4271/850204

[48] Benajes J, García A, Monsalve-Serrano J, Villalta D. Benefits of E85 versus gasoline as low reactivity fuel for an automotive diesel engine operating in reactivity controlled compression ignition combustion mode, Energy Conversion and Management, Volume 159, 2018, Pages 85-95.

\section{Abbreviations}

ATDC: After Top Dead Center

BTDC: Before Top Dead Center 
CAD: Crank Angle Degree

CA50: Crank angle at 50\% mass fraction burned

CDC: Conventional Diesel Combustion

$\mathrm{Cl}$ : Compression Ignition

CO: Carbon Monoxide

DOC: Diesel Oxidation Catalyst

DI: Direct Injection

DPF: Diesel Particulate Filter

EGR: Exhaust Gas Recirculation

EOI: End of Injection

EVO: Exhaust Valve Open

FSN: Filter Smoke Number

HC: Hydro Carbons

$\mathrm{HCCl}$ : Homogeneous Charge Compression Ignition

HRF: High Reactivity Fuel

ICE: Internal Combustion Engine

IMEP: Indicated Mean Effective Pressure

IVC: Intake Valve Close

LRF: Low Reactivity Fuel

LTC: Low Temperature Combustion

NOx: Nitrogen Oxides

ON: Octane Number

PCl: Premixed Compression Ignition

PFI: Port Fuel Injection

PPC: Partially Premixed Charge

PRR: Pressure Rise Rate

RCCI: Reactivity Controlled Compression Ignition

SOC: Start of Combustion

SCE: Single Cylinder Engine

SCR: Selective Catalytic Reduction

TPA: Three-Pressure Analysis 